\title{
Carbon Tax, Subsidy, and Emission Reduction: Analysis Based on DSGE Model
}

\author{
Haoran Li $(\mathbb{D})$ and Wei Peng (iD) \\ College of Economics and Management, Shandong University of Science and Technology, Qingdao 266590, China \\ Correspondence should be addressed to Wei Peng; pengweisd@sdust.edu.cn
}

Received 13 November 2020; Revised 5 December 2020; Accepted 8 December 2020; Published 21 December 2020

Academic Editor: Wei Zhang

Copyright (c) 2020 Haoran Li and Wei Peng. This is an open access article distributed under the Creative Commons Attribution License, which permits unrestricted use, distribution, and reproduction in any medium, provided the original work is properly cited.

\begin{abstract}
Carbon emission has negative externalities, which will cause severe natural and social problems. In recent years, more and more attention has been paid to carbon emission reduction issue both in academic and application fields. This paper aims to explore the impact of punitive carbon tax and incentive carbon emission reduction subsidy on economy and environment through the dynamic stochastic general equilibrium (DSGE) framework. The results show that both carbon tax and carbon emission reduction subsidy policies can help to reduce carbon emissions and to improve environment quality. In addition, carbon emission reduction subsidy has a positive impact on economy, while carbon tax has the opposite impact. It follows that the incentive carbon emission reduction policy is more conducive to the coordinated development of economy and environment. This research can be a guideline for the government to formulate carbon emission abatement policies from the perspective of coordinated development.
\end{abstract}

\section{Introduction}

With the continuous increase in production scale and carbon emission, the world is facing more and more severe environment problems such as air pollution and climate change. On the one hand, the report "global air condition 2019" released by the American Institute of Health Effects pointed out that air pollution ranked the fifth among all health risk factors in the world, ranking after dietary risk, hypertension, smoking, and high fasting blood glucose. On the other hand, the Intergovernmental Panel on Climate Change (IPCC) suggested that global warming needed to be limited to 1.5 degrees Celsius or the planet would experience devastating climate change by 2030. And Nordhaus pointed that carbon dioxide would be the first man-made emission to affect climate on a global scale by the end of the century [1]. In 2007, one of the IPCC's reports showed that, according to the annual data of different continents, human's impact on the climate system is clear and ceaselessly growing. If left unchecked, air pollution and climate change would increase the likelihood of severe, widespread, and irreversible risk on humans and ecosystems [2,3]. Therefore, it is urgent to reduce carbon emissions.
Facing the challenge of carbon emission reduction, China has proposed a green development path with Chinese characteristics in light of its unique national condition. The green development path is not only the inheritance of sustainable development but also the theoretical innovation of sustainable development in China [4]. It is also a major theoretical contribution of socialism with Chinese characteristics to the objective reality of global ecological environment deterioration [5]. China's green development path includes developing a low-carbon economy, developing a stronger circular economy, continuing to promote energy conservation, and reducing carbon emission. Among them, developing a low-carbon economy and reducing carbon emission will help to improve the deteriorating international ecological environment.

Previous studies have shown that both carbon tax and carbon emission reduction subsidy had a great impact not only on the economy but also on the environment (e.g., Nordhaus [6], Jeong et al. [7], and Acemoglu et al. [8, 9]). In order to analyze which policy is more conducive to balance the economic development and environmental improvement, this paper builds a DSGE framework including household, firm, government, and environment sector. The 
contributions lie in that as follows: (1) An environmental DSGE model is built to analyze the impact of carbon tax and carbon emission reduction subsidy on the economy and environment, which supplements the relevant literature of environmental DSGE modeling. (2) The results demonstrate that both the punitive carbon tax and incentive carbon emission reduction subsidy can reduce carbon emissions and promote the environment quality. (3) The difference between two carbon emission reduction policies is that carbon emission reduction subsidy is beneficial to both environment improvement and economy development, while carbon tax is only beneficial to the former, which indicates that incentive policy is more conducive to the coordinated development of economy and environment.

\section{Literature Review}

Facing the worsening environment problems, how to effectively abate carbon emissions has become an important practical issue [10]. Grossman and Krueger [11] first proposed the environmental Kuznets curve to analyze the relationship between environment pollution and GDP per capita. And they found an inverted $U$-shaped relationship between air pollutants and economic growth. Some researchers support the view of the environmental Kuznets curve. For example, Galeotti and Lanza [12] collected new types of data including carbon emission and GDP from more than 100 countries to verify the environmental Kuznets curve. In addition, there are also some researchers who were against Grossman and Krueger's view, such as Agras and Chapman [13] and He and Richard [14]. The environmental Kuznets curve only provides an influence mechanism for pollution emission on economic growth and the fact that the curve showed warned us to pay more attention to carbon emission reduction, which sparked a wave of research boom on it.

The above-mentioned scholars' studies on carbon emissions showed that the fundamental principle of carbon emission reduction policies is to stimulate carbon emission abatement initiatives or to directly curb carbon emissions, such as Choi's opinion on nonrenewable energy taxes and renewable energy subsidies [15]. As a result, carbon emission reduction policies can be divided into two aspects, one is the punitive policy such as imposing carbon tax to punish those who pollute, and the other is the incentive policy such as providing subsidies to stimulate those who make emission reduction efforts. Therefore, the government can control the firm's carbon emissions by formulating scientific and reasonable incentives and punitive carbon emission abatement policies. The following part combs the literature of these two aspects.

2.1. Punitive Carbon Tax Policy. Punitive carbon tax has been regarded as an effective carbon emission abatement policy with market features [16]. The concept of the environmental tax is first mentioned by Pigovian, which is, the government is able to adjust the negative externalities of the pollution through taxation [17], such as carbon tax policy. Jia and Lin
[18] applied a dynamic computable general equilibrium framework to study the Chinese carbon emission reduction strategy choice, and the results showed that the carbon tax is more effective than carbon trading. By reviewing literature about carbon tax, we found that most of them are linked to supply chain management. Yin et al. [19] investigated the optimal carbon emission policy in supply chain management and analyzed the implementation conditions of carbon tax and subsidy. Dou and Cao [20] explored the environmental and economic performances of the closed-loop supply chain under carbon tax policy and pointed out that a higher tax rate can bring better environmental performance. Zou et al. [21] developed a Stackelberg game to investigate the retailer's low-carbon investment decision on supply chain under carbon tax regulation and put forward a sharing contact which is beneficial to both economy and environment. Zhou et al. [22] reviewed plenty of literatures about supply chain management under carbon taxes, which shows that carbon tax is a powerful tool for carbon emission abatement. In addition, there are also some other studies on carbon tax. Chan [23] constructed an environmental DSGE model between two countries to determine the optimal carbon tax rate under different economic shocks. Zhang et al. [24] utilized an evolutionary game method to explore the manufacturer's green innovation-decision under carbon tax and innovation subsidy, and the results demonstrate that carbon tax is more effective than innovation subsidy. Zhu et al. [25] studied the green financial strategies for Chinese energy companies under carbon tax and concluded that the carbon tax can be conducive to help energy companies achieve green development.

The viewpoints of the above scholars have all verified that the carbon tax is a powerful and widely applied carbon emission reduction policy. Therefore, it is of great significance to study the impact of carbon tax on economy and environment.

\subsection{Incentive Carbon Emission Reduction Subsidy Policy.} Incentive carbon emission reduction subsidy policy is capable of promoting the firms' carbon emission abatement initiatives [26]. Argentiero et al. [27] built a DSGE model that included carbon taxes and subsidies to compare the cost-effectiveness under technology-driven shock and demand-driven shock. Xu et al. [28] studied the interaction scenario in which the government imposes carbon taxes on manufacturers and gives subsidies to consumers who purchase green products. Su et al. [29] developed a Stackelberg game to investigate the optimal pricing strategies under different subsidy modes, such as subsidy to manufacturers who produce low-carbon products or consumers who buy low-carbon products. Cao et al. [30] explored the optimal production and carbon emission abatement level in the context of cap-and-trade and low-carbon subsidy policies and discussed which policy is more beneficial to society. Han et al. [26] used game theory to study the optimal decisions in the low-carbon e-commerce supply chain, and the results showed that the government subsidy can help to encourage the manufacturer to produce low-carbon products. On the 
basis of the above researchers, subsidy policy is an effective way to stimulate the firm's carbon emission abatement initiatives.

By combining the above literatures on carbon tax and carbon emission reduction subsidy, we found that there is barely research studied the carbon tax and carbon emission reduction subsidy policies' impact both on economy and environment. Therefore, based on the previous researches, our work aims to investigate the economic and environmental impact of carbon tax and carbon emission reduction subsidy, which would supplement the literature gap in this field and provide theoretical reference for policy-makers.

\section{Model}

In this part, we construct a DSGE framework which consists of household, firm, government, and environment sectors. The logic among each sector of the proposed DSGE model is as follows: the household supplies labor and capital to firm, gains wage income, and capital return and makes the optimal consumption, labor, and capital decisions by maximizing the lifetime utility under the constraint of the budget. The firm input technology, capital, labor, and green production factor to obtain the profitable product, pays for production factor and carbon emission reduction cost, pays carbon tax to the government, gets carbon emission reduction subsidies from the government, and pursues profit maximization. The government satisfies the budget constraint and balances its books. The environment sector follows the dynamic equation of ecological environment quality. The logical structure of each sector under carbon tax and carbon emission reduction subsidy policies is shown in Figure 1.
3.1. Household. Household's utility is influenced by consumption, labor, and environment quality. The abstract form of household objective function is set as follows:

$$
\max E_{0} \sum_{t=0}^{\infty} \beta^{t} U\left(C_{t}, N_{t}, Q_{t}\right)
$$

where $E_{0}$ is the conditional expectation operator formed based on the information of phase $0.0<\beta<1$ represents the subjective discount rate. $U(\cdot), C_{t}, N_{t}$, and $Q_{t}$ are household utility function, consumption, labor, and environment quality.

The household aims to maximize its intertemporal utility. Referring to the research by Annicchiarico and Diluiso [31], the concrete form of household utility function can be described as follows:

$$
U\left(C_{t}, N_{t}, Q_{t}\right)=\frac{C_{t}^{1-\theta_{1}}}{1-\theta_{1}}-\frac{N_{t}^{1+\theta_{2}}}{1+\theta_{2}}+\eta \ln Q_{t},
$$

where $\theta_{1}$ and $\theta_{2}$ are the relative risk aversion elasticity of household consumption and labor supply, respectively. $\eta$ represents household's preferences for environment quality.

Household's budget constraint is set as follows:

$$
C_{t}+I_{t}=R_{K, t} K_{t}+W_{t} N_{t}
$$

where $I_{t}$ and $K_{t}$ represent household's investment and capital, respectively. $R_{K, t}$ and $W_{t}$ are capital return rate and wage level, respectively.

The equation of capital motion can be written as follows:

$$
I_{t}=K_{t+1}-(1-\delta) K_{t}
$$

where $\delta \in(0,1)$ represents the capital depreciation rate.

According to formulas (1)-(3), the household's Lagrange function can be depicted as follows:

$$
L_{F, t}=E_{0} \sum_{t=0}^{\infty} \beta^{t}\left\{\begin{array}{c}
\frac{C_{t}^{1-\theta_{1}}}{1-\theta_{1}}-\frac{N_{t}^{1+\theta_{2}}}{1+\theta_{2}}+\eta \ln Q_{t} \\
+\xi_{t}\left[C_{t}+K_{t+1}-\left(1-\delta+R_{K, t}\right) K_{t}-W_{t} N_{t}\right]
\end{array}\right\},
$$

where $\xi_{t}$ represents the Lagrange multiplier, that is, the shadow price. By solving the first-order partial derivatives of (5) with respect to consumption, labor, and capital, the optimal conditions of the household can be calculated as follows:

(1) Let $\partial L_{t} / \partial C_{t}=0$; one can obtain the following equation:

$$
\xi_{t}=-C_{t}^{-\theta_{1}}
$$

(2) Let $\partial L_{t} / \partial N_{t}=0$; one can obtain the following equation:

$$
W_{t}=N_{t}^{\theta_{2}} C_{t}^{\theta_{1}}
$$

(3) Let $\partial L_{t} / \partial K_{t}=0$; one can obtain the following equation:

$$
\left(\frac{C_{t}}{C_{t-1}}\right)^{\theta_{1}}=\beta\left(1+R_{K, t}-\delta\right)
$$

3.2. Firm. The firm aims to maximize its profits denoted by the difference between incomes and costs. The incomes mainly include sales volume and carbon emission subsidies. The costs mainly include labor wage, capital rent, green production factor cost, carbon tax, and carbon emission abatement cost. Assuming that the firm's production function meets the form of the Cobb-Douglas production function as follows: 


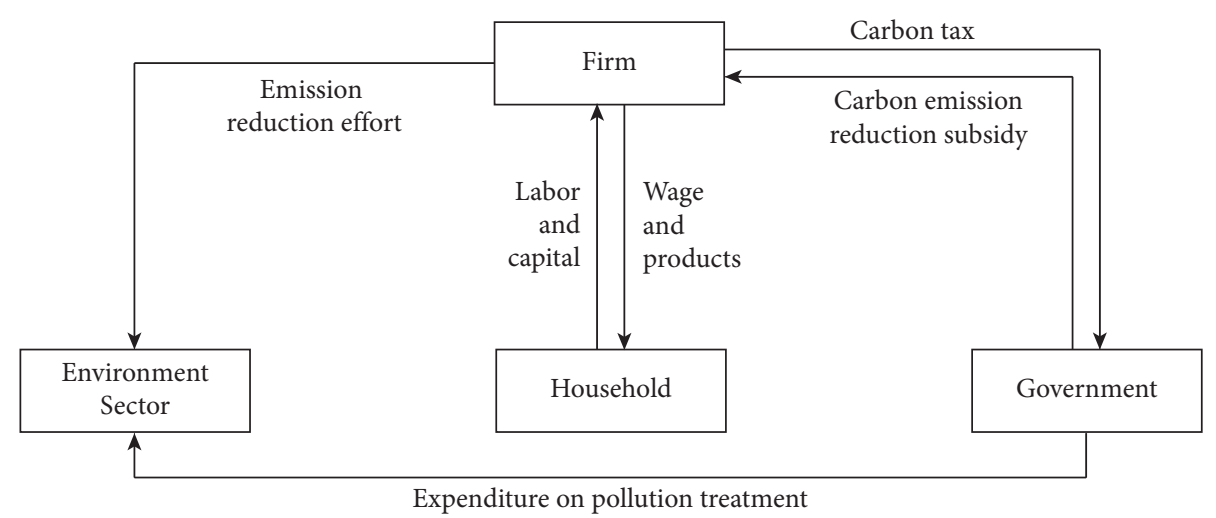

FIgURE 1: Logic structure diagram of the DSGE model.

$$
Y_{t}=A_{t} K_{t}^{\alpha_{1}} N_{t}^{\alpha_{2}} S_{t}^{1-\alpha_{1}-\alpha_{2}},
$$

where $Y_{t}, A_{t}, K_{t}, N_{t}$, and $S_{t}$ are firm's output, technical level, capital input, labor force input, and green production factor input at time $t$, respectively. $\alpha_{1}$ and $\alpha_{2}$ represent firm's capital and labor output elasticity, respectively. Assuming that the firm's technical level is subject to the exogenous shocks of the AR (1) process as follows:

$$
\ln A_{t}=\left(1-\rho_{A}\right) \ln A^{*}+\rho_{A} \ln A_{t-1}+e_{A, t},
$$

where $\rho_{A}$ and $A^{*}$ are the first-order autoregressive coefficient and the steady-state value of the technical level, respectively. $e_{A, t}$ represents the exogenous impact on the firm's technical level, which obeys the standard normal distribution.

Referring to the studies by Annicchiarico and Di Dio [32] and Heutel [33], we suppose that the firm would reduce its carbon emissions in pursuit of a more environmental friendly productive way under the carbon tax and carbon emission subsidy policies. Therefore, the actual carbon emission quantity can be depicted as

$$
X_{t}=\kappa Y_{t}\left(1-\mathrm{ER}_{t}\right)
$$

where $X_{t}$ and $\mathrm{ER}_{t}$ are the actual carbon emission quantity and carbon emission reduction efforts of the firm, respectively. $\kappa$ represents the carbon emission coefficient per unit output.

According to equation (11), the carbon emission reduction quantity $\mathrm{RX}_{t}$ can be described as follows:

$$
\mathrm{RX}_{t}=\kappa \mathrm{ER}_{t} Y_{t}
$$

Referring to the research by Chan [23], the firm's carbon emission reduction cost $\mathrm{ERC}_{t}$ is set as follows:

$$
\mathrm{ERC}_{t}=\mu_{1}\left(\mathrm{ER}_{t}\right)^{\mu_{2}} Y_{t}
$$

where $\mu_{1}>0$ and $\mu_{2}>1$ refer to the technical parameters of the firm's carbon emission reduction cost.

The firm's carbon emission reduction effort belongs to green behavior, which helps to improve the quality of ecological environment. Therefore, according to the carbon emission reduction quantity, the firm will get carbon emission reduction subsidy which can be depicted as follows:

$$
G_{2, t}=\psi_{t} \mathrm{RX}_{t}
$$

where $G_{2, t}$ is the government's carbon emission reduction subsidy to the firm. $\psi_{t}$ denotes carbon emission reduction subsidy rate at time $t$, and we assume $\psi_{t}$ is subject to the exogenous shocks of the AR (1) process as follows:

$$
\ln \psi_{t}=\left(1-\rho_{\psi}\right) \ln \psi^{*}+\rho_{\psi} \ln \psi_{t-1}+e_{\psi, t},
$$

where $\rho_{\psi}$ and $\psi^{*}$ are the first-order autoregressive coefficient and the steady-state value of the carbon emission reduction subsidy rate, respectively. $e_{\psi, t}$ represents the exogenous impact on the carbon emission reduction subsidy rate, which obeys the standard normal distribution.

In conclusion, the firm's objective function can be depicted as follows:

$$
\pi_{t}=Y_{t}-K_{t} R_{K, t}-N_{t} W_{t}-\mathrm{ERC}_{t}-\tau_{X, t} X_{t}-p_{S, t} S_{t}+G_{2, t},
$$

where $\pi_{t}$ represents the firm's total profit. $\tau_{X, t}$ denotes the carbon tax rate at time $t$, which is assumed to be subject to the exogenous impact of the AR (1) process as follows:

$$
\ln \tau_{X, t}=\left(1-\rho_{\tau_{X}}\right) \ln \tau_{X}^{*}+\rho_{\tau_{X}} \ln \tau_{X, t-1}+e_{\tau_{X}, t},
$$

where $\rho_{\tau_{X}}$ and $\tau_{X}^{*}$ are the first-order autoregressive coefficient and the steady-state value of the carbon tax rate, respectively. $e_{\tau_{X}, t}$ represents the exogenous impact on the carbon tax rate, which obeys the standard normal distribution.

Suppose that the green production factor price $p_{S, t}$ obeys the following exogenous shock of AR (1) process:

$$
\ln p_{S, t}=\left(1-\rho_{p_{S}}\right) \ln p_{S}^{*}+\rho_{p_{S}} \ln p_{S, t-1}+e_{p_{S}, t},
$$

where $\rho_{p_{S}}$ and $p_{S}^{*}$ are the first-order autoregressive coefficient and the steady-state value of the green production factor price, respectively. $e_{p_{s}, t}$ represents the exogenous impact on the green production factor price, which obeys the standard normal distribution.

By solving the first-order partial derivatives of equation (16) with respect to capital input, labor input, green production factor input, and carbon emission reduction efforts, we can get the following conditions: 
(1) Let $\partial \pi_{t} / \partial K_{t}=0$; one can obtain the optimal capital input:

$$
R_{K, t}=\frac{\alpha_{1}\left(1-\mu_{1}\left(\mathrm{ER}_{t}\right)^{\mu_{2}}+\kappa\left(\tau_{X, t} \mathrm{ER}_{t}+\psi_{t} \mathrm{ER}_{t}-\tau_{X, t}\right)\right) Y_{t}}{K_{t}} .
$$

(2) Let $\partial \pi_{t} / \partial N_{t}=0$; one can obtain optimal labor input:

$$
W_{t}=\frac{\alpha_{2}\left(1-\mu_{1}\left(\mathrm{ER}_{t}\right)^{\mu_{2}}+\kappa\left(\tau_{X, t} \mathrm{ER}_{t}+\psi_{t} \mathrm{ER}_{t}-\tau_{X, t}\right)\right) Y_{t}}{N_{t}} .
$$

(3) Let $\partial \pi_{t} / \partial S_{t}=0$; one can obtain the optimal green production factor input:

$$
p_{S, t}=\frac{\left(1-\alpha_{1}-\alpha_{2}\right)\left(1-\mu_{1}\left(\mathrm{ER}_{t}\right)^{\mu_{2}}+\kappa\left(\tau_{X, t} \mathrm{ER}_{t}+\psi_{t} \mathrm{ER}_{t}-\tau_{X, t}\right)\right) Y_{t}}{S_{t}} .
$$

(4) Let $\partial \pi_{t} / \partial \mathrm{ER}_{t}=0$; one can obtain the optimal carbon emission reduction effort:

$$
\mathrm{ER}_{t}=\left(\frac{\kappa\left(\psi_{t}+\tau_{X, t}\right)}{\mu_{1} \mu_{2}}\right)^{1 / \mu_{2}-1} .
$$

3.3. Government. We assume that the government mainly applied carbon tax levied from firms into pollution treatment and carbon emission reduction subsidy. Therefore, the government's balance equation can be depicted as follows:

$$
\tau_{X, t} X_{t}=G_{1, t}+G_{2, t} .
$$

Among it, the government's expenditure on pollution treatment $G_{1, t}$ obeys the following exogenous shock of AR (1) process:

$$
\ln G_{1, t}=\left(1-\rho_{G_{1}}\right) \ln G_{1}^{*}+\rho_{G_{1}} \ln G_{1, t-1}+e_{G_{1, t}},
$$

where $\rho_{G_{1, t}}$ and $G_{1}^{*}$ are the first-order autoregressive coefficient and the steady-state value of the government's expenditure on pollution treatment, respectively. $e_{G_{1, t}}$ represents the exogenous impact on the government's expenditure on pollution treatment, which obeys the standard normal distribution.

3.4. Environment Sector. Referring to the research by Jouvet [34], the ecological environment quality at time $t$ is related to its initial state, the state at time $t-1$, the firm's carbon emission, and the government's pollution treatment. Therefore, the dynamic equation of environment quality $Q_{t}$ is set as follows:

$$
Q_{t}=h \bar{Q}+(1-h) Q_{t-1}-X_{t}+\gamma G_{1, t},
$$

where $Q_{t-1}$ represents the environment quality at time $t-1$. $h$ denotes the environment's self-purification capacity. $\bar{Q}$ represents the initial environment quality. $\gamma$ refers to the government's pollution treatment efficiency.

3.5. Market Clearing Condition. The market-clearing condition means that the firm's output is equal to all summed up by the household's consumption and capital accumulation, the government's expenditure, and the firm's emission reduction cost which also includes green production factor input cost. It is assumed that all the household's capital is invested in the firm's production and only the clearing out of the commodity market is considered. Therefore, the marketclearing condition satisfies the following equation:

$$
Y_{t}=C_{t}+I_{t}+G_{1, t}+\mathrm{ERC}_{t}+p_{S, t} S_{t} .
$$

\section{Parameters and Impulse Response Analysis}

There are two types of parameters in the DSGE model: static and dynamic parameters. The static parameters which reflect the model's static characteristics are usually determined by the calibration method. The dynamic parameters which reflect the model's dynamic characteristics are mostly settled by the estimation method.

4.1. Static Parameters Calibration. On the household's side, the static parameters that need to be calibrated include $\beta, \theta_{1}$, $\theta_{2}, \eta$, and $\delta$. On the firm's side, the static parameters comprise $\alpha_{1}, \alpha_{2}, \kappa, \mu_{1}$, and $\mu_{2}$. On the environment sector's side, the static parameters contain $\bar{Q}, h$, and $\gamma$. Referring to the studies by Annicchiarico and Di Dio [32], Heutel [33], Chan [23], and Fischer and Springborn [35], the abovementioned static parameters' definitions and calibrated values are shown in Table 1.

4.2. Dynamic Parameters Estimation. The proposed DSGE model includes 5 exogenous shocks: $e_{\tau_{X}, t}, e_{\psi, t} e_{A, t}, e_{G_{1}, t}$, and $e_{p_{\mathrm{s}}, t}$. To estimate the dynamic parameters, we select China's GDP from 1996 to 2018 as the external observation data. The parameters to be estimated in the determining equation of each exogenous shock include the first-order autoregressive coefficient and the random disturbance term. Referring to the research studies by Gerali et al. [36] and Khan et al. [37], we select the prior mean values, set that the first-order auto regression parameters satisfy that the beta distribution and the fluctuation parameters (random shocks) is subject to the relatively smooth inverse gamma (Inv. Gamma) distribution. We use Dynare (11.4) toolbox under Matlab (2017b) software to estimate the posterior distribution of dynamic parameters under a given prior distribution by the Bayesian estimation method.

The Bayesian estimation results of dynamic parameters are shown in Table 2, and the prior distribution and posterior distribution diagrams are shown in Figure 2.

\section{Results and Analysis}

In this section, we analyzed the impulse response of five economic variables including the output $Y_{t}$, consumption 
TABLE 1: Calibration results of static parameters.

\begin{tabular}{lcc}
\hline Parameter & Definition & Value \\
\hline$\beta$ & Household discount factor & 0.97 \\
$\theta_{1}$ & Relative risk aversion elasticity of consumption & 0.8 \\
$\theta_{2}$ & Inverse of the Frisch elasticity of labor supply & 0.2 \\
$\eta$ & Household environment preference coefficient & 1 \\
$\delta$ & Capital depreciation rate & 0.11 \\
$\alpha_{1}$ & Elasticity of output with respect to capital & 0.4 \\
$\alpha_{2}$ & Elasticity of output with respect to labor & 0.45 \\
$\kappa$ & Carbon emission factor per unit of output & 0.16 \\
$\mu_{1}$ & Coefficient of mitigation costs scale & 0.2 \\
$\mu_{2}$ & Emission reduction effort index & 1.8 \\
$\bar{Q}$ & Initial environment quality & 1 \\
$\gamma$ & Environment self-purification capacity & 0.1 \\
\hline
\end{tabular}

TABLE 2: Bayesian estimation results of dynamic parameters.

\begin{tabular}{lcccc}
\hline Parameter & Prior distribution & Prior mean & Posterior mean & 90\% HPD interval \\
\hline$\rho_{G_{1}}$ & Beta & 0.6000 & 0.5986 & {$[0.5612,0.6332]$} \\
$\rho_{p_{S}}$ & Beta & 0.6000 & 0.5987 & {$[0.5693,0.6330]$} \\
$\rho_{\tau_{X}}$ & Beta & 0.6000 & 0.5953 & {$[0.5648,0.6296]$} \\
$\rho_{\psi}$ & Beta & 0.6000 & 0.6002 & {$[0.5737,0.6323]$} \\
$\rho_{A}$ & Beta & 0.6000 & 0.6098 & {$[0.5786,0.6452]$} \\
$e_{G_{1}, t}$ & Inv. Gamma & 1.0000 & 0.8219 & {$[0.4274,1.3774]$} \\
$e_{p_{S}, t}$ & Inv. Gamma & 1.0000 & 0.7857 & {$[0.3166,1.3662]$} \\
$e_{\tau_{X}, t}$ & Inv. Gamma & 1.0000 & 0.7272 & {$[0.2937,1.1170]$} \\
$e_{\psi, t}$ & Inv. Gamma & 1.0000 & 0.6747 & {$[0.2580,1.0403]$} \\
$e_{A, t}$ & Inv. Gamma & 1.0000 & 0.4782 & {$[0.3452,0.6078]$} \\
\hline
\end{tabular}
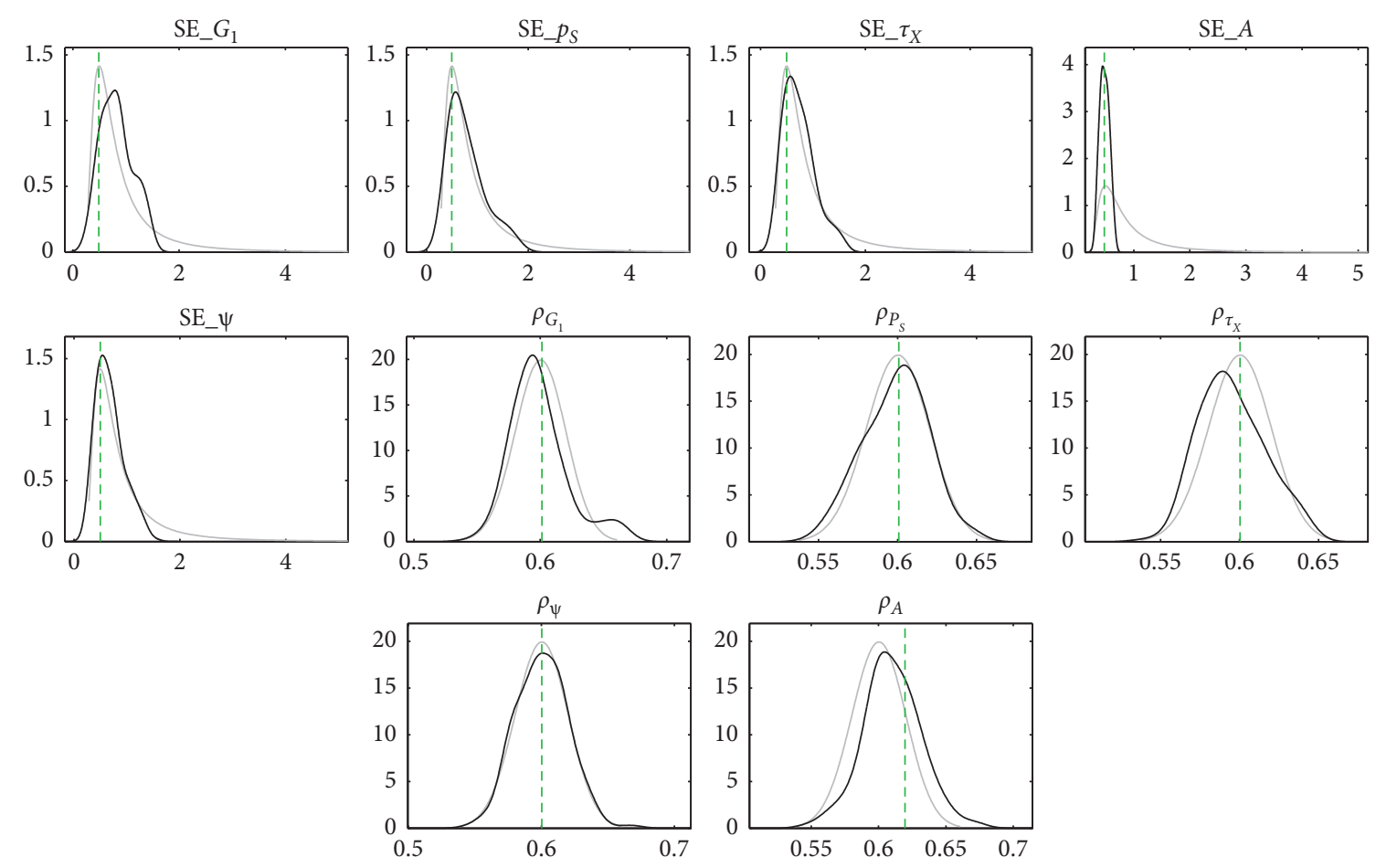

Figure 2: Prior and posterior distribution diagrams in Bayesian estimation. 

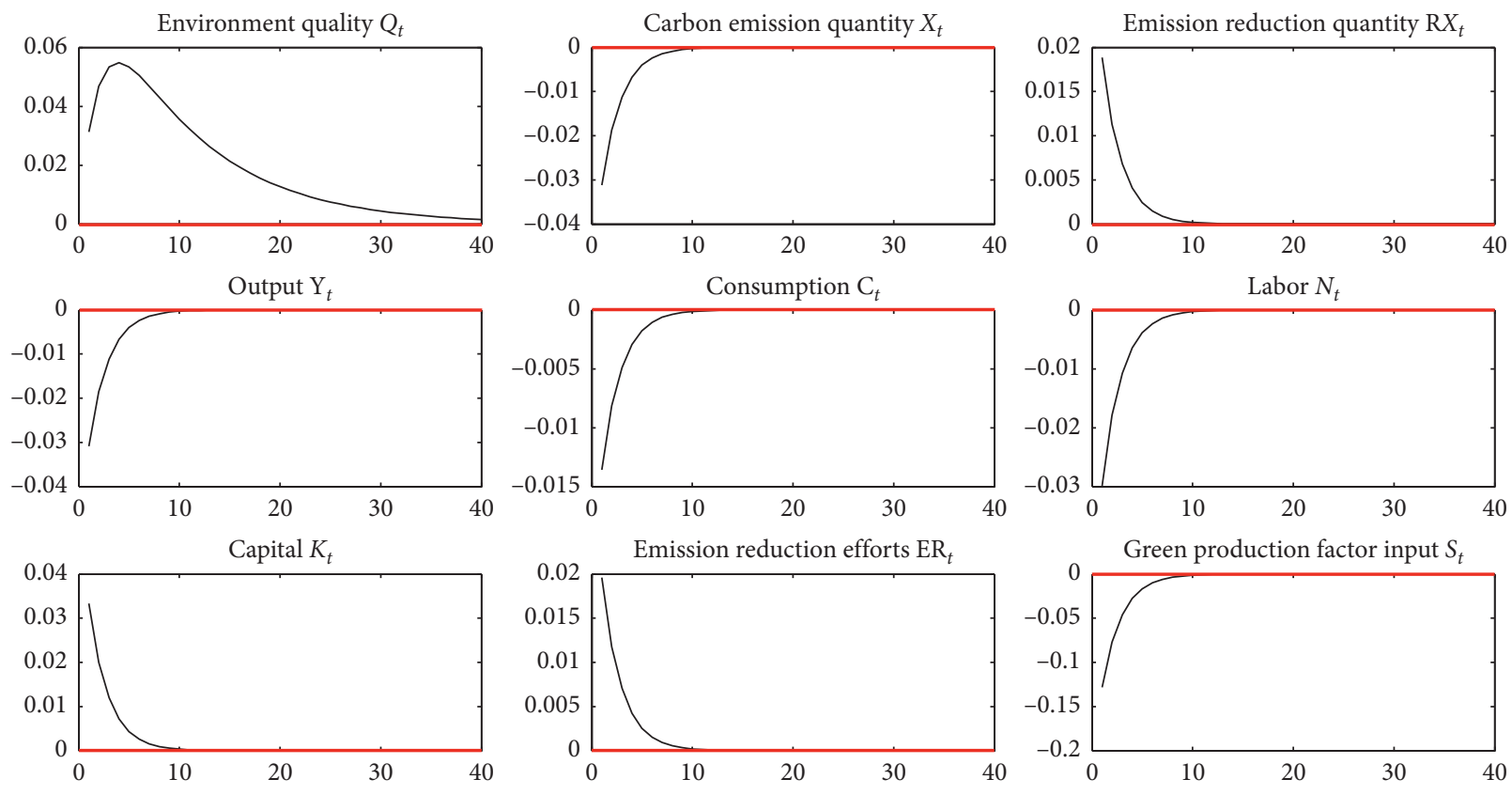

FIGURE 3: IRFs of carbon tax rate.

$C_{t}$, labor $N_{t}$, capital $K_{t}$, and green production factor input $S_{t}$, and four environment variables including environment quality $Q_{t}$, carbon emission quantity $X_{t}$, carbon emission reduction quantity $\mathrm{RX}_{t}$, and carbon emission reduction efforts $\mathrm{ER}_{t}$ under the shock of carbon tax rate and subsidy rate. The impulse response results of each variable are shown as follows.

\subsection{Impulse Response Functions (IRFs) of Carbon Tax Rate.} Figure 3 displays the IRFs of the carbon tax rate. The results showed that, in response to the carbon tax rate shock, $K_{t}$, $\mathrm{RX}_{t}$ and $\mathrm{ER}_{t}$, increased, while $X_{t}, Y_{t}, C_{t}, N_{t}$, and $S_{t}$ decreased before 10th period and all variables except $Q_{t}$ remained unchanged after the 10 th period. $Q_{t}$ reached the peak of growth around the 4th period, and then, the growth rate declined. That may because in order to avoid paying high carbon taxes, firms are willing to make more emission reduction efforts to reduce carbon emissions. Eventually, continuous efforts of the firm will significantly improve environment quality. Although the imposition of carbon tax brought a greater environment quality, it would lead to the decline of output, consumption, labor, and green production factor input. Therefore, the economic benefit of the carbon tax is not as good as its environmental benefit.

5.2. IRFs of Carbon Emission Reduction Subsidy Rate. Figure 4 displays the IRFs of carbon emission reduction subsidy rate. The results showed that, in response to the carbon emission reduction subsidy rate shock, except the descent of $X_{t}$ or the sustained growth of $Q_{t}$, all other variables increased before the $10^{\text {th }}$ period and remained unchanged after the 10th period. Under the impact of carbon emission reduction subsidy rate, both economic and environmental benefits can be well satisfied.

5.3. Sensitivity Analysis on Carbon Tax Rate. In order to further analyze the dynamic effect of the carbon tax rate shock and examine the correctness of the impulse response, we, respectively, raised and reduced the carbon tax rate by $15 \%$ and analyzed the impulse response of five economic and four environmental variables under these two conditions. The results of sensitivity analysis on the carbon tax rate shock are shown in Figure 5.

Comparing three different carbon tax levels, we concluded that increasing or decreasing the carbon tax rate level will enlarge the original positive impact effect, such as the impact on $Q_{t}, \mathrm{RX}_{t}, K_{t}$, and $\mathrm{ER}_{t}$ and will reduce the original negative impact effect, such as $X_{t}, Y_{t}, C_{t}, N_{t}$, and $S_{t}$. Whether the carbon tax rate is increased or decreased, the impact directions on the economic and environmental variables are consistent with the initial level, which verifies the robustness of the conclusion of IRFs.

5.4. Sensitivity Analysis on Carbon Emission Reduction Subsidy Rate. As same as the carbon tax rate, we, respectively, raised and reduced the carbon emission reduction subsidy rate by $15 \%$ and analyzed the impulse response of five economic and four environmental variables under these two conditions. The results of sensitivity analysis on the carbon emission reduction subsidy rate shock are shown in Figure 6.

Comparing three different carbon emission reduction subsidy rate levels, we concluded that increasing or decreasing the level of carbon emission reduction subsidy rate level will reduce the original negative impact effect on $X_{t}$ and enlarge the original positive impact effect on the other 

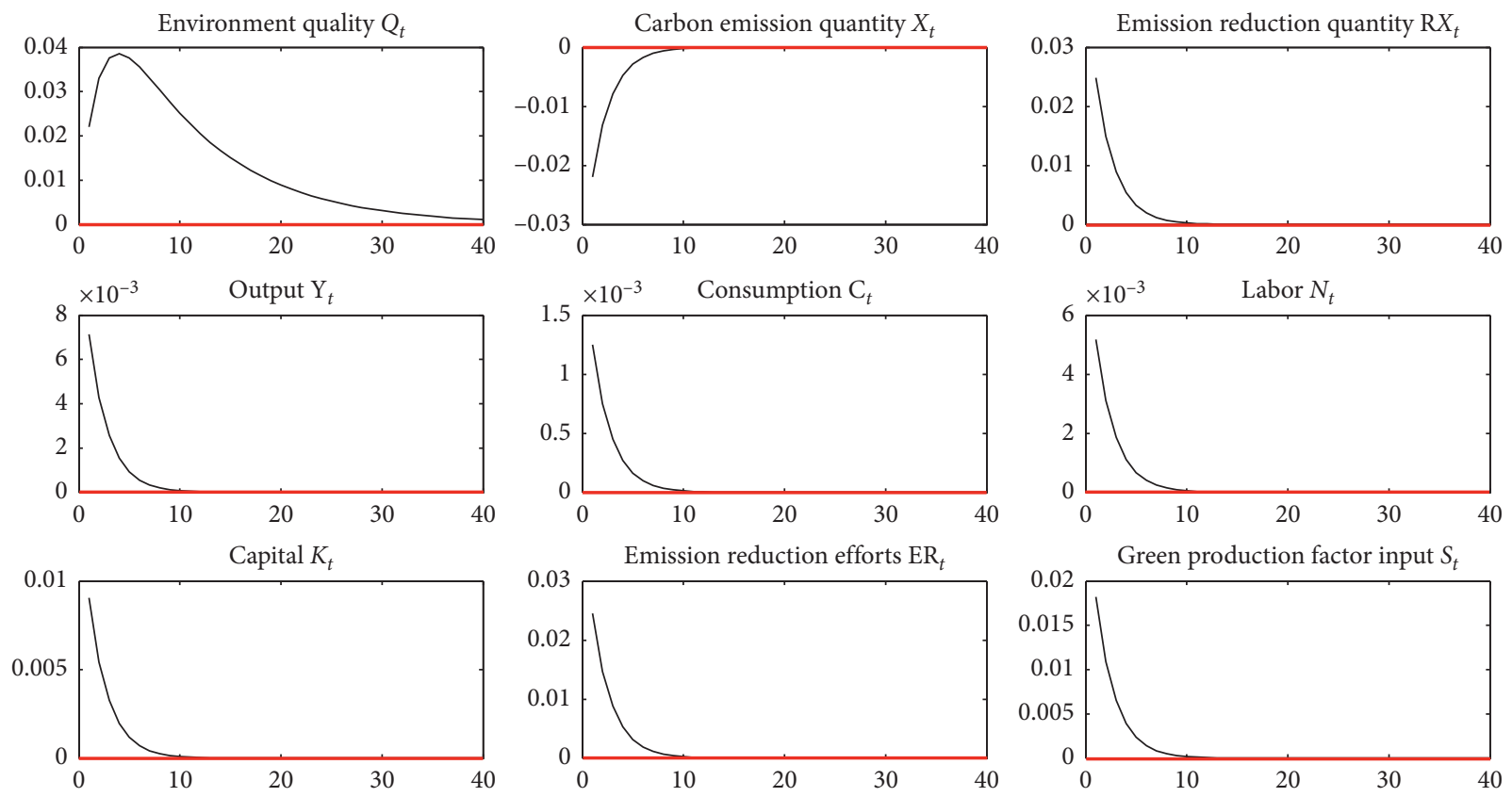

Figure 4: IRFs of carbon emission reduction subsidy rate.
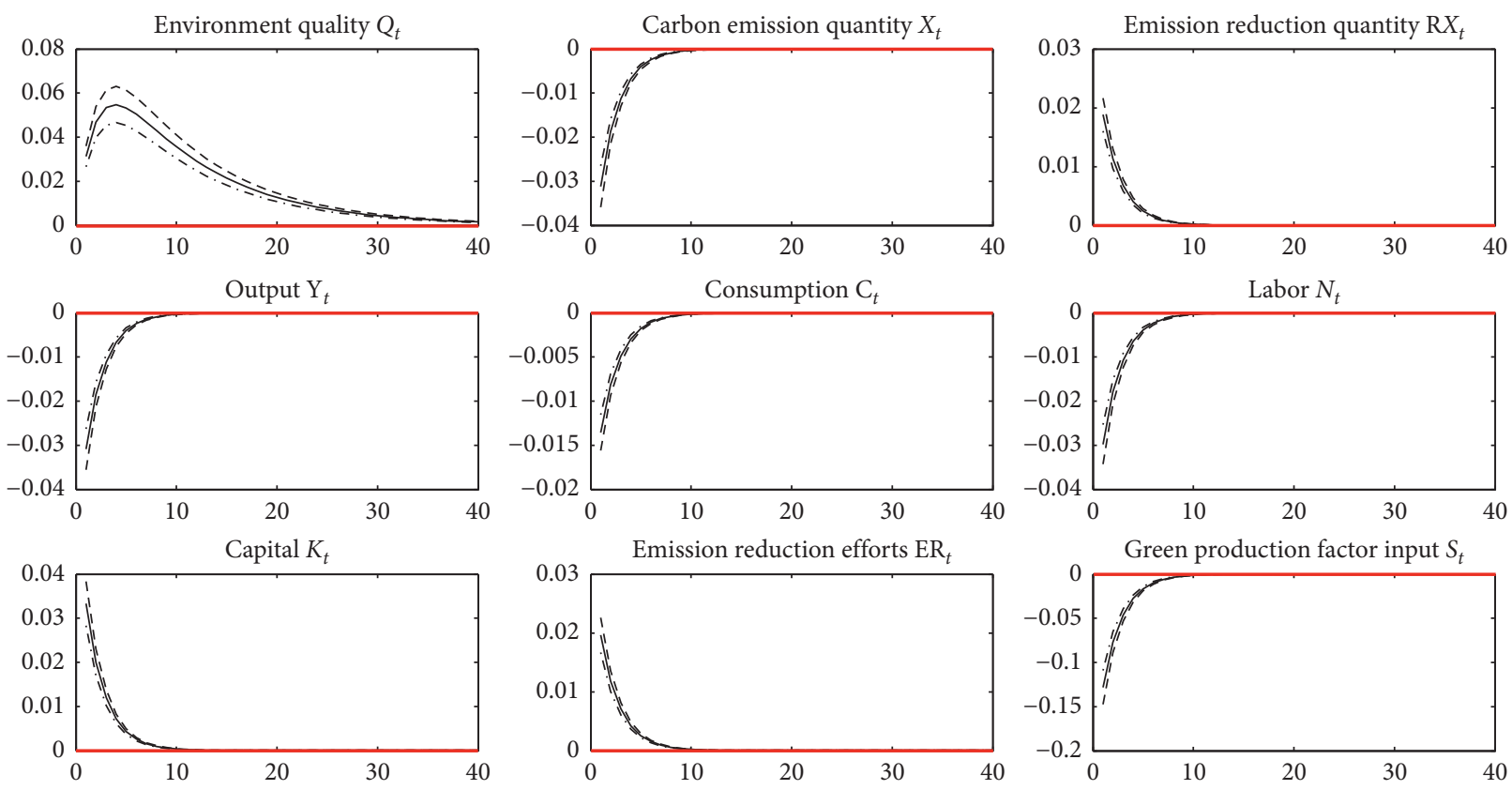

- Initial level of $\tau_{X}$

- - - $15 \%$ increase of $\tau_{X}$

..- $15 \%$ decrease of $\tau_{X}$

FIgURe 5: Sensitivity analysis on carbon tax rate. 

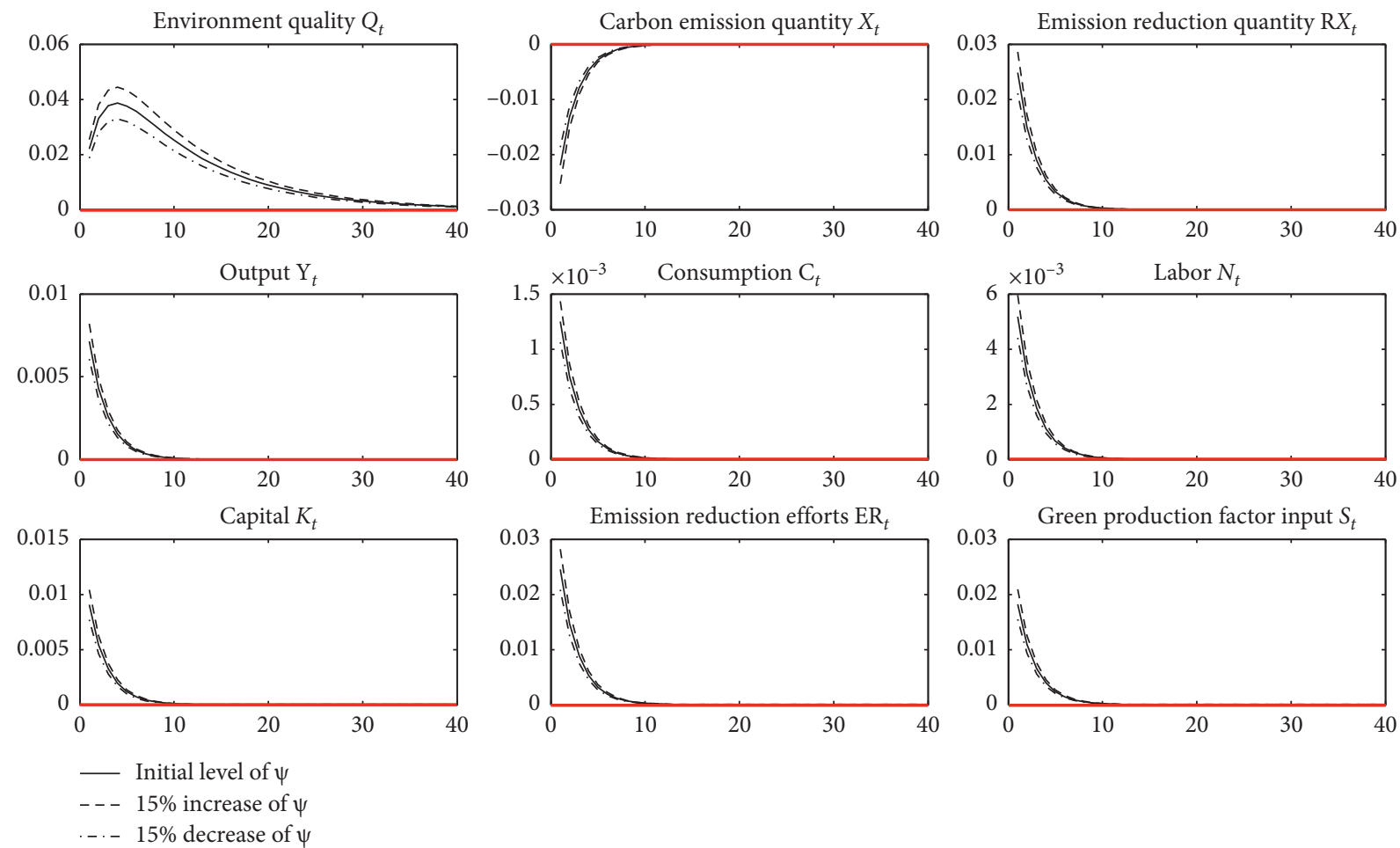

Figure 6: Sensitivity analysis on carbon emission reduction subsidy rate.

variables. The sensitivity analysis on the carbon emission reduction subsidy rate also verifies the robustness of the conclusion of IRFs.

\section{Conclusion}

This paper constructs an environmental DSGE framework to explore the impacts of carbon tax and carbon emission reduction subsidy policies on the environment and economy. Based on the results, we can draw the following conclusions:

(1) Both punitive carbon tax and incentive carbon emission reduction subsidy policies can help to increase a firm's emission reduction efforts, reduce carbon emissions in the short term, and improve environment quality in the long term.

(2) The difference between punitive carbon tax and incentive carbon emission reduction subsidy policies on the impact of economic variables lies in that the carbon tax will decrease the output, consumption, labor, and green production factor input, while carbon emission reduction subsidy will increase them.

(3) Increasing or decreasing the carbon tax rate and carbon emission reduction subsidy rate only cause slight fluctuations in economic and environmental variables, but do not change the impact direction.

This study has reference significance to a certain degree for policy-makers to formulate environmental policies from the perspective of coordinated development of economy and environment. However, our analysis is based on a new Keynesian framework, and future research might be more significant if extending the model to a more complex model with more sectors such as financial accelerators or open economy context.

\section{Data Availability}

The data used to support the findings of this study are available from the corresponding author upon request.

\section{Conflicts of Interest}

The authors declare that there are no conflicts of interest regarding the publication of this paper.

\section{Acknowledgments}

This work was supported by the Natural Science Foundation of Shandong Province (Grant no. ZR2016FM26) and National Social Science Foundation of China (Grant no. 16FJY008).

\section{References}

[1] W. D. Nordhaus, "Can we control carbon dioxide? (from 1975)," American Economic Review, vol. 109, no. 6, 2019.

[2] B. Xin and M. Sun, "A differential oligopoly game for optimal production planning and water savings," European Journal of Operational Research, vol. 269, no. 1, pp. 206-217, 2018.

[3] W. Zhang, M. Zhang, Q. Zhou, and X. Zhang, "What influences the effectiveness of green logistics policies? A 
grounded theory analysis," Science of The Total Environment, vol. 714, Article ID 136731, 2020.

[4] B. G. Xin, Oligopoly Games with Ecological Property Rights, Economic Science Press, Beijing, China, 2019.

[5] N. Liu, Complex Innovation Network in Nano-Energy, Economic Science Press, Beijing, China, 2017.

[6] W. D. Nordhaus, "Rolling the "DICE": an optimal transition path for controlling greenhouse gases," Resource and Energy Economics, vol. 15, no. 1, pp. 27-50, 1993.

[7] S.-J. Jeong, K.-S. Kim, J.-W. Park, D.-S. Lim, and S.-M. Lee, "Economic comparison between coal-fired and liquefied natural gas combined cycle power plants considering carbon tax: Korean case," Energy, vol. 33, no. 8, pp. 1320-1330, 2008.

[8] D. Acemoglu, P. Aghion, L. Bursztyn, and D. Hemous, "The environment and directed technical change," American Economic Review, vol. 102, no. 1, pp. 131-166, 2012.

[9] D. Acemoglu, U. Akcigit, D. Hanley, and W. Kerr, "Transition to clean technology," Journal of Political Economy, vol. 124, no. 1, pp. 52-104, 2016.

[10] B. Xin, W. Peng, and M. Sun, "Optimal coordination strategy for international production planning and pollution abating under cap-and-trade regulations," International Journal of Environmental Research and Public Health, vol. 16, no. 18, p. 3490, 2019.

[11] G. Grossman and A. Krueger, "Environmental impacts of a North American free trade agreement," Social Science Electronic Publishing, vol. 8, 1992.

[12] M. Galeotti and A. Lanza, "Desperately seeking environmental Kuznets," Environmental Modelling \& Software, vol. 20, no. 11, pp. 1379-1388, 2005.

[13] J. Agras and D. Chapman, "A dynamic approach to the environmental Kuznets Curve hypothesis," Ecological Economics, vol. 28, no. 2, pp. 267-277, 1999.

[14] J. He and P. Richard, "Environmental Kuznets curve for $\mathrm{CO}_{2}$ in Canada," Ecological Economics, vol. 69, no. 5, pp. 1083-1093, 2010.

[15] J.-K. Choi, B. R. Bakshi, K. Hubacek, and J. Nader, "A sequential input-output framework to analyze the economic and environmental implications of energy policies: gas taxes and fuel subsidies," Applied Energy, vol. 184, pp. 830-839, 2016.

[16] H. Zhao, S. Song, Y. Zhang et al., "Optimal decisions in supply chains with a call option contract under the carbon emissions tax regulation," Journal of Cleaner Production, vol. 271, 2020.

[17] B. Lanz, J.-D. Wurlod, L. Panzone, and T. Swanson, "The behavioral effect of Pigovian regulation: evidence from a field experiment," Journal of Environmental Economics and Management, vol. 87, pp. 190-205, 2018.

[18] Z. Jia and B. Lin, "Rethinking the choice of carbon tax and carbon trading in China," Technological Forecasting and Social Change, vol. 159, 2020.

[19] X. Yin, X. Chen, X. Xu et al., "Tax or subsidy? optimal carbon emission policy: a supply chain perspective," Sustainability, vol. 12, no. 4, 2020.

[20] G. W. Dou and K. Y. Cao, "A joint analysis of environmental and economic performances of closed-loop supply chains under carbon tax regulation," Computers \& Industrial Engineering, vol. 146, 2020.

[21] F. Zou, Y. J. Zhou, and C. H. Yuan, "The impact of retailers' low-carbon investment on the supply chain under carbon tax and carbon trading policies," Sustainability, vol. 12, no. 9, p. 27, 2020.

[22] X. Zhou, X. Wei, J. Lin et al., "Supply chain management under carbon taxes: a review and bibliometric analysis,"
Omega-International Journal of Management Science, vol. 98, 2021.

[23] Y. T. Chan, "Collaborative optimal carbon tax rate under economic and energy price shocks: a dynamic stochastic general equilibrium model approach," Journal of Cleaner Production, vol. 256, p. 29, 2020.

[24] S. Z. Zhang, Y. M. Yu, Q. H. Zhu et al., "Green innovation mode under carbon tax and innovation subsidy: an evolutionary game analysis for portfolio policies," Sustainability, vol. 12 , no. 4 , p. $22,2020$.

[25] N. P. Zhu, Y. Y. Bu, M. L. Jin et al., "Green financial behavior and green development strategy of Chinese power companies in the context of carbon tax," Journal of Cleaner Production, vol. 245, 2020.

[26] Q. Han, Y. Wang, L. Shen et al., "Decision and coordination of low-carbon E-commerce supply chain with government carbon subsidies and fairness concerns," Complexity, vol. 2020, Article ID 1974942, 19 pages, 2020.

[27] A. Argentiero, C. A. Bollino, S. Micheli, and C. Zopounidis, "Renewable energy sources policies in a Bayesian DSGE model," Renewable Energy, vol. 120, pp. 60-68, 2018.

[28] C. Y. Xu, C. X. Wang, and R. B. Huang, "Impacts of horizontal integration on social welfare under the interaction of carbon tax and green subsidies," International Journal of Production Economics, vol. 222, p. 13, 2020.

[29] C. Su, X. J. Liu, and W. Y. Du, "Green supply chain decisions considering consumers' low-carbon awareness under different government subsidies," Sustainability, vol. 12, no. 6, p. 12, 2020.

[30] K. Cao, X. Xu, Q. Wu, and Q. Zhang, "Optimal production and carbon emission reduction level under cap-and-trade and low carbon subsidy policies," Journal of Cleaner Production, vol. 167, pp. 505-513, 2017.

[31] B. Annicchiarico and F. Diluiso, "International transmission of the business cycle and environmental policy," Resource and Energy Economics, vol. 58, p. 29, 2019.

[32] B. Annicchiarico and F. Di Dio, "GHG emissions control and monetary policy," Environmental and Resource Economics, vol. 67, no. 4, pp. 823-851, 2017.

[33] G. Heutel, "How should environmental policy respond to business cycles? Optimal policy under persistent productivity shocks," Review of Economic Dynamics, vol. 15, no. 2, pp. 244-264, 2012.

[34] P.-A. Jouvet, P. Michel, and G. Rotillon, "Optimal growth with pollution: how to use pollution permits?" Journal of Economic Dynamics and Control, vol. 29, no. 9, pp. 1597-1609, 2005.

[35] C. Fischer and M. Springborn, "Emissions targets and the real business cycle: intensity targets versus caps or taxes," Journal of Environmental Economics and Management, vol. 62, no. 3, pp. 1597-1609, 2011.

[36] A. Gerali, S. Neri, L. Sessa, and F. M. Signoretti, "Credit and banking in a DSGE model of the euro area," Journal of Money, Credit and Banking, vol. 42, pp. 107-141, 2010.

[37] H. Khan and J. Tsoukalas, The Quantitative Importance of News Shocks in Estimated DSGE Models, Carleton University, Ottawa, Canada, 2009. 